\title{
Prevalence of gastrointestinal parasites in domestic pigeons and backyard chickens in Kalar and Khanaqin districts, Iraq
}

\author{
Omer Mahmood Amin, Sarkawt Radha Kakabwa
}

Biology Department, College of Education, University of Garmian

\begin{abstract}
Domestic pigeons and backyard chickens are reared by a large number of people in Iraq for several purposes including meat, egg, commerce, and hobby. They are infected with different types of parasites which cause high mortality rate and great economic loss. The present study was conducted in two districts in Garmian region, Kalar and Khanaqin to study the prevalence of gastrointestinal parasites in domestic pigeons and backyard chickens. A total of 720 fresh fecal samples from (401 backyard chickens and 319 domestic pigeons) were examined using direct microscopy and standard floatation technique. The overall prevalence of parasites was $38.61 \%$. The rate of infection in chickens was $32.91 \%$ (132/401) and the rate of infection in pigeons was $45.76 \%(146 / 319)$. Five genera of nematodes were identified in chickens: Ascaridia galli (5.98\%), Heterakis gallinarum (4.48\%), Capillaria sp. (3.24\%), Oxyspirura mansoni (1.74\%) and Trichostrongylus tenuis $(0.75 \%)$. Two cestodes were also identified, Choanotaenia infundibulatum (6.73\%) and Raillietina sp. (0.75\%) and one protozoan, Eimeria sp. $(15.96 \%)$. Five genera of parasites were identified in domestic pigeons as follows: three nematodes, Ascaridia columbae (2.82\%), Heterakis gallinarum $(1.25 \%)$ and Capillaria sp. $(0.62 \%)$, one cestode, Raillietina sp. $(1.56 \%)$ and one protozoan, Eimeria sp. (42\%). Sexes of the birds had no effect on the rate of infection p>0.05. Regarding locations, pigeons from Khanaqin were highly infected with parasites compared to Kalar $\mathrm{p}<0.05$. Although most of the studied birds were infected with a single form of parasite, multiple infections were observed at high rate in chickens compared to pigeons $\mathrm{p}<0.05$. This is the first investigation of endoparasites intensity of domestic pigeons and backyard chickens in these two areas .
\end{abstract}

\section{Introduction}

Domesticated chickens and pigeons are raised all over the world for the purposes of meat, egg production, feather, in addition to other commercial purposes (Appleby et al., 2004). While farmed poultry is mostly raised in special places or in villages away from cities, yet there is still a large number of people rear them in small cities .

Chickens and pigeons are social animals; therefore, they are more susceptible to infection with different species of internal and external parasites (Eslami et al., 2009). The effects of parasites on poultry vary from the reduction in meat, egg production, retarding of growth and development and in the worst scenarios death in case of high infections or untreated conditions (Kumar et al., 2015). Nematodes such as Ascaridia galli, Heterakis gallinarum, and Capillaria sp. have been categorized among the common parasites of chickens and domestic pigeons in Iraq (Abdulla and Mohammed, 2013; Al-Jaumeili and Aljoburi, 2015; Al-Zubaidei, 2015). Oxyspirura mansoni, eye worm of poultry, is a less common nematode and frequently known to infect single birds, however, in endemic regions where the intermediate host is abundant, the entire flock can be affected (Santoyo-De-Estéfano et al., 2014). Cestodes such as Raillietina sp. and Chonotaenia infundibulatum have been studied in chickens in Iraq and found to cause weight loss and intestinal destruction in the infected birds (Abd et al., 2017). Eimeria sp. is also considered as a very common protozoan parasite in domestic chickens and pigeons and many species of it have been investigated in Iraq (Aljoburi, 2018). Ascaridia columbae is regarded as the most common pathogenic parasites of pigeons. It is the causative agent of ascariasis in pigeons and other types of poultry (Sari et al., 2008; Al-Barwari and Saeed, 2012). The parasite causes diarrhea, growth reduction, low production, and 
enteritis (Sivajothi and Sudhakara, 2015). Due to the nowadays orientation of people towards raising domesticated birds and the lack of studies on poultry parasites in our region, the researchers aimed to study the prevalence of gastrointestinal parasites in domesticated pigeons and free-range backyard chickens in Kalar-Al-Sulaymaniyah and Khanaqin-Diyala which are two close districts belong to two different governorates, and the trade of chickens and pigeons is regularly performed between the two areas .

\section{Materials and Methods}

The present study was carried out in two districts in Garmian region, Kalar-Sulaimaniyah and Khanaqin-Diyala and the villages around them from March 2018 to February 2019 (Figure 1). A total of 720 fresh fecal samples from 401 backyard chickens aged 1-2 years (79 male and 322 female) and 319 domestic pigeons (134 male and 185 female) were collected from the study areas (Figure 1). Out of the 401 chicken fecal samples, 175 (25 male, 150 female) were collected from Khanaqin and 226 (54 male, 172 female) from Kalar. Regarding pigeons, 134 fecal samples (64 male, 69 female) were collected from Khanaqin and 186 (70 male, 116 female) from Kalar.

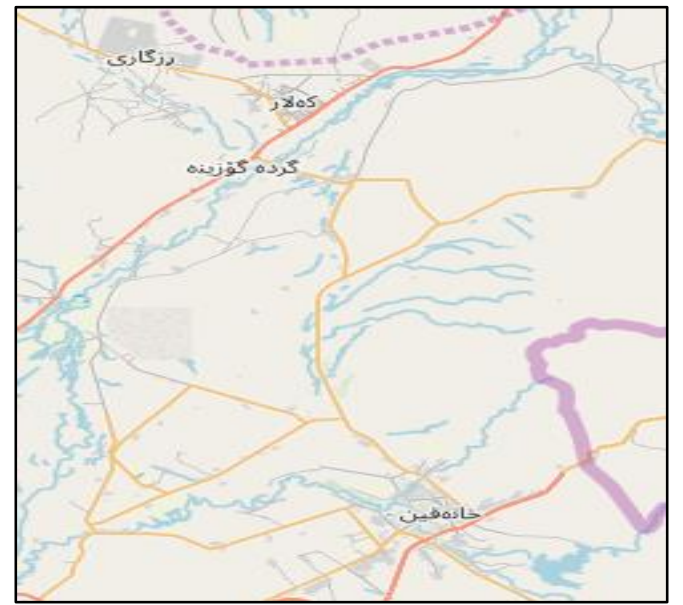

Figure 1: Areas of sample collection

Fresh fecal samples were obtained by isolating individual chickens and pigeons in cardboard boxes for a period in the day time or for overnight. After that, the samples were collected in plastic disposable containers and transferred directly to the laboratories of Biology Department, Garmian University for parasitic identifications. Two gm from each sample was preserved in tubes containing $10 \%$ formalin for further use. The remainder was tested using direct microscopy and standard floatation technique (Kumar et al., 2015). For floatation technique, $2 \mathrm{gm}$ of the collected droppings were added to $10 \mathrm{ml}$ test tubes containing $5 \mathrm{ml}$ of salt floatation solution (400 gm of sodium chloride dissolved in $1000 \mathrm{ml}$ distilled water). The tubes were shaken very well till homogenized mixture was obtained. After that, the mixture was filtered using tea sieve to get rid of the big fecal residues and the filtrate was centrifuged at $1200 \mathrm{rpm}$ for 5 minutes. Finally, the tubes were gently filled with more floatation solution to the tip, then covered with coverslips and left for 15 minutes. The coverslips were then placed on glass slides and visualized under high-quality compound microscope under 10 and $40 \mathrm{X}$ magnifications respectively. Identification of the parasite species was based on the morphological characteristics of the eggs and oocysts based on (Soulsby, 1986; Bizhga et al., 2011; Kumar et al., 2015). Chi-square test was applied for analyzing different variables in the current study using Graphpad PRISM software version 6.1. The level of significance was set at $\mathrm{p}$ value less than 0.05 for all hypotheses tested in this study .

\section{Results}

The overall parasitic infection rate in both domestic pigeons and backyard chickens was $38.61 \%$ (278/720). The rate of infection in chickens was 32.91\% (132/401), while the rate of infection in the domestic pigeons was $45.76 \%(146 / 319)$ as summarized in (Table 1).

Table 1: Prevalence of gastrointestinal parasites in domestic pigeons and backyard chickens in Kalar and Khanaqin districts

\begin{tabular}{|l|l|l|l|}
\hline Source of fecal sample & No. of samples & No. infected & Infection rate \% \\
\hline Backyard chicken & 401 & 132 & 32.91 \\
\hline Domestic pigeon & 319 & 146 & 45.76 \\
\hline Total & 720 & 278 & 38.61 \\
\hline
\end{tabular}


Eight genera of parasites were identified in chickens, five of them were nematodes: infection rate with nematodes was 17.95\% (72/401) and they were Ascaridia galli, Heterakis gallinarum, Capillaria sp., Oxyspirura mansoni, and Trichostrongylus tenuis. Two cestodes were also identified and comprised 7.48\% (30/401) as follows: Choanotaenia infundibulatum and Raillietina sp. Eimeria was the only protozoan parasite identified in chickens $15.96 \%$ (64/401) there was a significant difference between the rate of infections of the parasite types $\mathrm{P}<0.05$ (Table 2 ).

Five genera of parasites were observed in domestic pigeons: Ascaridia culumbae, Raillietina sp., Capillaria sp., Heterakis gallinarum, and Eimeria sp. (table 2). Eimeria sp. showed the most common parasite $42 \%$ in pigeons (134/319), followed by nematodes $5.64 \%$ (18/319) and cestodes $1.56 \%(5 / 319)$ respectively. A significant difference was observed between infection with the various parasites $\mathrm{P}<0.05$.

Table 2: Prevalence of gastrointestinal parasites according to parasite types and species

\begin{tabular}{|c|c|c|c|c|c|}
\hline \multirow{9}{*}{$\begin{array}{l}\text { Backyard } \\
\text { chickens }\end{array}$} & $\begin{array}{l}\text { Samples } \\
\text { examined }\end{array}$ & Parasite type & $\begin{array}{l}\text { Infection } \\
\text { rate \% }\end{array}$ & Parasite name & $\begin{array}{l}\text { Infection rate } \\
\%\end{array}$ \\
\hline & \multirow{8}{*}{401} & Protozoa & 15.96 & Eimeria sp. & $15.96 * * * *$ \\
\hline & & \multirow{5}{*}{ Nematodes } & \multirow{5}{*}{$17.95^{* * * *}$} & Ascaridia galli & 5.98 \\
\hline & & & & Heterakis gallinarum & 4.48 \\
\hline & & & & Capillaria sp. & 3.24 \\
\hline & & & & Oxyspirura mansoni & 1.74 \\
\hline & & & & Trichostrongylus tenuis & 0.75 \\
\hline & & \multirow[t]{2}{*}{ Cestodes } & \multirow[t]{2}{*}{7.48} & $\begin{array}{l}\text { Choanotaenia } \\
\text { infundibulatum }\end{array}$ & 6.73 \\
\hline & & & & Raillietina $s p$. & 0.75 \\
\hline \multirow{5}{*}{$\begin{array}{l}\text { Domestic } \\
\text { pigeons }\end{array}$} & \multirow{5}{*}{319} & Protozoa & $42 * * * *$ & Eimeria sp. & $42 * * * *$ \\
\hline & & \multirow{3}{*}{ Nematodes } & \multirow{3}{*}{5.64} & Ascaridia columbae & 2.82 \\
\hline & & & & Heterakis gallinarum & 1.25 \\
\hline & & & & Capillaria sp. & 0.62 \\
\hline & & Cestode & 1.56 & Raillietina sp. & 1.56 \\
\hline
\end{tabular}

The rate of infection in chickens in Kalar was $33.62 \%$ (76/226) and in Khanaqin was 32\% (56/175), there was no significant difference between chicken infection rates in the two areas $\mathrm{P}>0.05$. The prevalence of parasites in domestic pigeons in Kalar was 37.09\% (69/186), whereas in Khanaqin it was 57.89 (77/133). The Khanaqin infected pigeons were significantly higher than that of Kalar $\mathrm{P}<0.05$ (Table 3 ).

Table 3: Prevalence of gastrointestinal parasites in domestic pigeons and backyard chickens according to areas of the study.

\begin{tabular}{|l|l|l|l|l|}
\hline Examined bird & Area & Samples examined & No. infected & Infection rate \% \\
\hline \multirow{2}{*}{ Chicken } & Kalar & 226 & 76 & 33.62 \\
\cline { 2 - 5 } & Khanaqin & 175 & 56 & 32 \\
\hline \multirow{2}{*}{ Pigeon } & Kalar & 186 & 69 & 37.09 \\
\cline { 2 - 5 } & Khanaqin & 133 & 77 & $57.89 * * *$ \\
\hline
\end{tabular}

Male chickens were infected at a rate of $35.44 \%$ (28/79) which was almost close to the rate of infection in female 31.98 (103/322) P>0.05. Likewise, no significant difference was observed between the rate of infection in male 47.01\% (63/134) and female pigeons 45.94\% (85/185) P>0.05 (Table 4). Multiple infections (infections with more than one parasite) were observed more frequently in chickens $9.23 \%$ (37/401) than those of pigeons 5.01\% (16/319) $\mathrm{P}<0.05$ (Table 5).

Table 5: Prevalence of multiple infections in domestic pigeons and backyard chickens

\begin{tabular}{|l|l|l|l|}
\hline Bird type & Samples examined & $\begin{array}{l}\text { No. of birds with multiple } \\
\text { infections }\end{array}$ & Infection rate \% \\
\hline Chicken & 401 & 37 & $9.23 *$ \\
\hline Pigeon & 319 & 16 & 5.01 \\
\hline
\end{tabular}



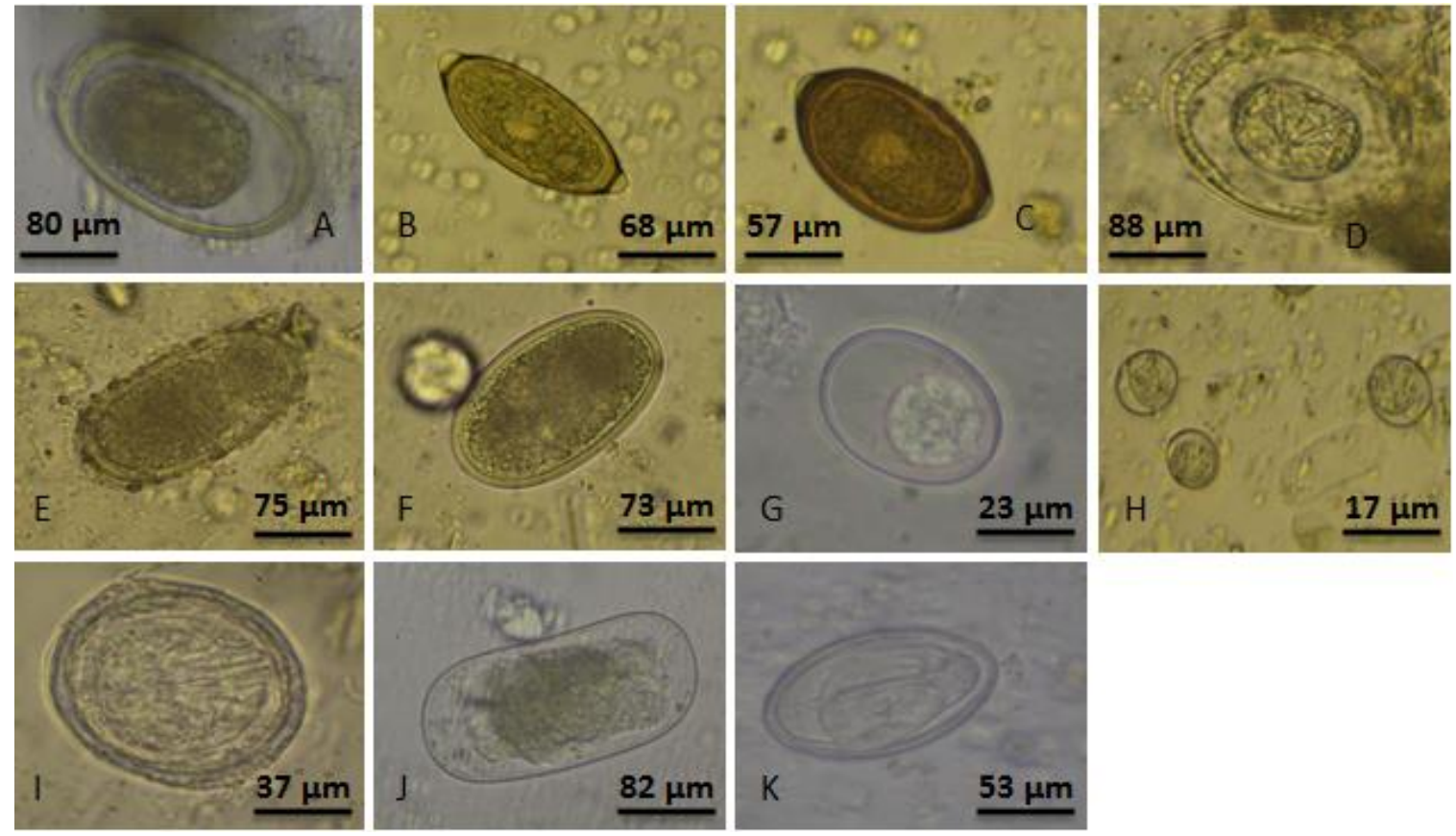

Figure 2: Ova and oocysts identified from fecal samples of domestic pigeons and backyard chickens: A: Ova of Ascaridia galli (40X), B,C: ova of Capillaria sp. (40X), D: ova of Raillietina sp. (40X), E: ova of Heterakis gallinarum (40X), F: ova of Ascaridia columbae, G,H: oocycsts of Eimeria sp. (100, 40X), I: ova of Choanotaenia infundibulatum (40X), J: ova of Trichostrongylus tenuis (40X), K: ova of Oxyspirura mansoni (40X).

\section{Discussion}

Out of the 720 fecal samples collected from domestic pigeons and backyard chickens, 278 of them appeared to harbor at least one type of internal parasite $38.61 \%$. The total rate of infection in chickens in this study was $32.91 \%$ (132/401). Free-range chickens have access to outdoor pens and are allowed to roam and forage freely, therefore, they become in contact with insects, earthworms and snails which are the intermediate host required to complete the life cycle of many poultry parasites.

Five genera of nematodes were recovered in chickens with the infection rate of $(17.95 \%)$. Parasites, particularly helminthes cause loss of weight, anemia, intestinal inflammation, destruction of intestinal villi, reduction in egg laying and food intake (Idika et al., 2016; Abd et al., 2017). Ascaridia galli showed the highest rate among the parasitic nematodes $5.98 \%$. It was lower than the findings of other researchers in Iraq and the neighbor countries (Al-Alousi, 2008; Eslami et al., 2009; Al-Zughaibi and Al-Ghazawi, 2010; Al-Saeed and Al-Badrani, 2014; Yagoob et al., 2107). While it was higher than the study conducted by (Aljoburi, 2018) on broiler chicken in Samarra city in which the rate of chicken infection with Ascaridia galli was $3.18 \%$. In this study, $4.48 \%$ of the chickens were infected with Heterakis gallinarum, the nematode that transmits the protozoa Histomonas meleagridis, the causative agent of histomoniasis in poultry. Abdullah and Mohammed (2012) observed a high rate of infection with the parasite $81 \%$ when they carried out a study on the prevalence of ecto and endoparasites of domestic chickens in Sulaimani region. On the other hand, the results were found to be comparable with the study of (Al-Zubaidei, 2015). Capillaria sp. infected 3.24\% of the examined chickens. A similar study was carried out by Al-Saeed and Al-Badrani (2014) in Duhok province, Kurdistan region and the rate of infection was $4.1 \%$. Oxyspirura mansoni was found to infect $1.74 \%$ of chickens. The morphology and size of the eggs were in agreement with what reported by Soulsby, (1986) and Santoyo-De-Estéfano et al., (2014). The reason for the presence of this parasite is due to the availability of cockroaches which work as an intermediate host for the parasite. 
Cockroaches were found sometimes around the chicken coops. Trichostrongylus tenuis was the least nematode seen in this study $0.75 \%$. Kumar et al. (2015) reported $1.72 \%$ infection with this parasite when they carried out a similar study on domestic chickens in India .

Two species of cestodes were identified in chickens, Choanotaenia infundibulatum $6.73 \%$ and Raillietina sp. $0.75 \%$. This is in line with the findings of (Al-Zughaibi, 2010) and lower than that reported by (AlSaeed and Al-Badrani, 2014). Nonetheless, Soulsby (1986), reported that Raillietina sp. represent the second most common helminthes in poultry after Ascaridia sp. The variations in the rate of chicken infection with cestodes may be attributed to the difference in availability of the intermediate hosts. The most common and devastating of protozoan diseases in poultry is coccidiosis. Coccidiosis is usually more problematic in chicks and growing pullets and is usually the prime suspect in the cause of death especially at the ages of 3-6 weeks (Abd et al., 2017). Eimeria sp. was the only protozoan parasite recovered in this study. The prevalence of Eimeria sp. in chickens was 15.96\%. Other researchers have also reported a high prevalence of Eimeria sp. (Hadipour et al., 2013; Kumar et al., 2013; Ybañez et al., 2018). The reason for the high prevalence of coccidian parasites could be the direct life cycle of the parasite, hence if the coop is not cleaned regularly, the chickens will refeed on the contaminated droppings, therefore the parasite stays, circulate and infects the entire flock.

Pigeon farming can be a great income source for the people in poor countries; others rear them for hobbies, religious rituals, in addition to their importance in feeding on hazardous insects (Dranzoa et al., 1999). Likewise, pigeons are known to carry endoparasites such as helminthes and protozoa. In the current study the parasite Emeria sp. showed the highest parasite community in domestic pigeons $42 \%$. This finding is in agreement with other researchers (Sivajothi and Sudhakara, 2015; Hasan et al., 2018). A study has been carried out by Wahhab et al (2018) to record parasites of the buccal cavity of domestic pigeons and dove in Garmian region, the only parasite they reported was Trichomonas gallinae (21.69\%). Three nematodes were also identified in pigeons in the current study with a rate of 5.64\%. Ascaridia columbae is considered as the most common and problematic parasite of domestic pigeons and dove causing ascariasis (Boado et al., 1992). Prevalence of this parasite has been reported in pigeons to reach 90\% (Bizhga et al., 2011). Capillaria sp. and Heterakis gallinarum were found in small proportions in pigeons in the present study. The low rate of infection with nematodes in comparison to chickens may be attributed to the fact that pigeons are reared in closed areas and less frequently mix with the neighbor flocks. Therefore, if there is originally no infection in the pigeon flock there will be less chance they can get the infection. Riellietina sp. was also among the cestode parasites identified in pigeons in this study with a rate of $1.56 \%$. The Khanaqin infected pigeons were significantly higher than that of Kalar $\mathrm{P}<0.05$. High prevalence has also been reported in Iran and Iraq (Radfar et al., 2011; Abed et al., 2014). The high prevalence in Khanaqin pigeons compared to Kalar could be due to, first, the trade of pigeons between Khanaqin and the on boarder cities of Iran. Second, there may be a variation in the distribution and availability of intermediate hosts. Third, in the rural areas domestic pigeons forage alongside dove and rock pigeons, therefore, they have the opportunity to get infections with new parasites and with higher proportions. It is also possible that pigeon raising in Kalar has better managerial and are more hygienic having better veterinary care than those in Khanaqin.

Sexes of the poultry studied had no effect on the infection rates. This is in agreement with others (AlBayati and Al-amary, 2012; Al-Saeed and Al-Badrani, 2014). In contrary, others have found significant differences in the rate of parasitic infection between male and female pigeons (Abed et al., 2014). Male and female live in the same place and share the same coop; therefore, they have almost equal chances to get infections with parasites. The majority of chickens and pigeons infections were infections with single parasite species. However, the difference in multiple infections between the two studied poultry types was obvious. For example, multiple infections were observed in 37 (9.23\%) chickens in comparison to only 16 $(5.01 \%)$ cases in pigeons. In conclusions, chickens and pigeons in Garmian region carry protozoa, nematodes, and cestodes parasites and proper actions have to be taken to reduce the rate of infection in order to have healthier poultry in these two areas.

\section{References}

.1 Abd, S.S., Mohammed, S.A., and Kadir, M.A. (2017). Study of pathological effect caused by certain parasites in the digestive tract of broiler chickens in Kirkuk city. Journal of Tikrit University for Agricultural Sciences. 17(1), 119-123. 
.2 Abdullah, S.H., and Mohammed, A.A. (2013). Ecto and Endo parasites prevalence in domestic chickens in Sulaimani region. The Iraqi Journal of Veterinary Medicine. 37(2), 149-155.

.3 Abed, A.A., Naji, H.A., and Rhyaf, A.G. (2014). Investigation study of some parasites infected domestic pigeon (Columba livia domestica)in Al-Dewaniya city. IOSR-JPBS. 9(4), 13-20.

4 Al-Alousi, M.T. (2008). Prevalence of internal parasites in municipal chicken in villages of Falluja - Iraq. Anbar J. of Agri. Sci. 6(2), 268-270.

.5 Al-Barwari S., and Saeed I. (2012). The parasitic communities of the rock pigeon Columba livia from Iraq: component and importance. Turkish Society for Parasitology 36(4), 232-239.

.6 Al-Bayati, S.T., and Alamary, A.M. (2012). Isolate some external parasites in some types of family Columbidae in the city of Baghdad. 11th Scientific conference. College of Veterinary medicine. 157-164.

.7 AL-jaumeili, A.H., and Aljoburi, M.H. (2015). The parasites that infect the females for domestic fowl (Gallus Gallus Domesticus) in the villages of the city of Sharqat, Salah Al-Deen province. Journal of Tikrit University for Agricultural Sciences. 15(4), 144-148.

.8 Aljoburi, A.M. (2018). Survey study of most important diseases which infected the broiler farms in Samarra city. Journal Tikrit Univ. For Agri. Sci. 18(4), 131-138.

.9 Al-Saeed., A.T., and AL-Badrani, M.A. (2014). Study of the parasites of the local chickens (Gallus gallus domesticus) in Duhok province, Kurdistan region Iraq. Journal of University of Zakho. 2(1), $18-23$.

10 Al-Zubaidei, H.H. (2015). Isolation and identification of some ecto and endoparasites on native chickens in Diyala province. Al-Qadisiyah Journal of veterinary Medicine Sciences. 14(2), 1-5.

.11 Al-Zughaibi, I. M., and Al-Ghazawi, A.K. (2010). Epidemiological study of distribution of parasites in the digestive tract of backyard chicken in Babylon governorate. J. Karbala Uni. 8(2), 161-163.

.12 Appleby, M.C., Mench J.A., and Hughes, B.O. (2004). Poultry behavior and welfare. CABI publishing, Cambridge, MA. pp: 48-57.

.13 Bizhga, B., Sotiri E., Boçari, A., and Kolleshi, D. (2011). Ascaridia columbae in Columbia livia domestica. Albanian J. Agric. Sci. 2(10), 7-12 .

.14 Boado, E., Zaldivar, L., and Gonzales, A. (1992). Diagnosis, report and incidence of diseases of the pigeon (Columba livia) in Cuba. Rev Cubana de-Ciencia Avicola. 19, 74-78.

.15 Dranzoa, C., Ocaido, M and Katete P. (1999). The ecto-, gastro-intestinal and haemo-parasites of live pigeons (Columba livia) in Kampala, Uganda. Avian Pathology. 28, 119-124.

.16 Eslami, A., Ghaemi, P., and Rahbari, S. (2009). Parasitic infections of free-range chickens from Golestan province, Iran. Iranian J Parasitol. 4(3), 10-14.

.17 Hadipour, M.M., Olyaie, A., Naderi, M., Azad., and Nekouie, O. (2013). Prevalence of Eimeria species in scavenging native chickens of Shiraz, Iran. African Journal of Poultry Farming. 1 (2), 34-36.

.18 Hasan, M.H., Al Abbadi, A.E., and Abdul Rahman, N.R. (2018). A Study of endoparasites of pigeons in Mosul city. Rafidain Journal of Science. 27(1), 76-81.

.19 Idika, K., Obi, C.F., Ezeh, I.O., Iheagwam, C.N., Njoku, I.N., and Nwosu, C.O. (2016). Gastrointestinal helminth parasites of local chickens from selected communities in Nsukka region of south eastern Nigeria. J Parasit Dis. 40(4), 1376-1380.

.20 Kumar, S., Garg, R., Ram, H., Maurya, P.S., Banerjee, P.S. (2015). Gastrointestinal parasitic infections in chickens of upper gangetic plains of India with special reference to poultry coccidiosis. J Parasit Dis. 39(1), 22-26.

.21 Radfar, M.H., Khedri, J., Adinehbeigi, K., Nabavi, R., and Rahmani, K. (2012). Prevalence of parasites and associated risk factors in domestic pigeons (Columba livia domestica) and free-range backyard chickens of Sistan region, east of Iran. J Parasit Dis. 36(2), 220-225.

.22 Santoyo-De-Estefano, F.A., Espinoza-Leija, R.R., Zarate-Ramos, J.J., and Hernandez-Velasco, X. (2014). Identification of Oxyspirura mansoni (Spirurida:Thelaziidae) in a free-range hen (Gallus gallus domesticus) and its intermediate host, surinam cockroach (Pycnosselus surinamensis) in Monterey, Nuevo Leon, Mexico. Acta Zoológica Mexicana. 30(1), 106-113.

.23 Sari, B., Karatepe, B., Karatepe, M and Kara, M. (2008). Parasites of domestic (Columba livia domestica) and wild (Columba livia livia) pigeons in Nigde, Turkey. Bull Vet Inst Pulawy 52, 551-554.

.24 Sivajothi, S., and Sudhakara, R.B. (2015). A study on the gastro intestinal parasites of domestic pigeons in YSR Kadapa district in Andhra Pradesh, India. J Dairy Vet Anim Res. 2(6), 216-218. 
.25 Soulsby, E. J. L. (1986). Helminths, Arthropodes and protozoa of domesticated Animals. 7 eds. Bailliere Tindal, London, U.K. pp: 99-166.

.26 Wahhab, M.A., Abdulrahman, N.R., and Ali, S.A. (2017). A study of oropharyngeal parasites infection in doves and domestic pigeons in some villages of Garmian -Iraqi Kurdistan region. KJAR. 2(1), $1-6$.

.27 Yagoob, G., Khaki, A., Feizi3, A., Raza, H.A., Khan, R., Hao, L Hosseini, M., Irfan ullah., Sherein S. Abdelgayed., Kakar8, M., Piras, C., and Yang, L.G. (2017). Epidemiological and pathological studies on the helminthic parasites in native chickens of Tabriz city, Iran. genetics and molecular Research $16(4), 1-8$.

.28 Ybañez, R.H., Resuelo, K.J., Kintanar, A.P., and Ybañez, A.P. (2018). Detection of gastrointestinal parasites in small-scale poultry layer farms in Leyte, Philippines. Veterinary World. 11(11), 1587-1591. 